\title{
TRABALHO DOCENTE E CAPITALISMO: UM ESTUDO CRÍTICO DA PRODUÇÃO ACADÊMICA DA DECADA DE 1990
}

\author{
Paulo Sergio Tumolo* \\ Klalter Bez Fontana*
}

\begin{abstract}
RESU M 0: 0 texto apresenta uma análise da produção investigativa sobre 0 trabalho docente da década de 1990 no Brasil, identificando as principais concepções sobre o tema e o tratamento analítico desenvolvido pelos pesquisadores. N um primeiro momento, expõe, de maneira sucinta, os resultados obtidos a partir do estudo realizado, para depois desenvolver uma análise da produção sobre o trabalho docente à luz do referencial marxista. Para tanto, empreende-se um estudo do significado do trabalho no capitalismo e das diferenciações entre processo de trabalho e processo de produção de capital, bem como da compreensão do conteúdo de trabalho produtivo de capital. Esta base permitiu trazer à tona a questão da relação entre os trabalhadores docentes e as classes sociais, o que reabre a discussão sobre o papel dos professores, não apenas como professores, mas sobretudo como classe, no processo de transformação revolucionária do capitalismo.
\end{abstract}

Palavras-chave: Trabalho docente. C apitalismo. Classe proletária.

\section{TEACHERS' WORK AND CAPITALISM:}

\section{A CRITICAL STUDY OF THE ACADEMIC PRODUCTION IN THE 1990S}

ABST RACT : The text provides an analysis of the investigations carried out on teachers' work in the 1990s in Brazil, identifying the main conceptions on the theme and the researchers' analytical approach.

* Doutor em Educação e professor do Centro de Ciências da Educação e do Programa de Pós-G raduação em Educação da U niversidade Federal de Santa Catarina (UFSC). E-mail: tumolo@ced.ufsc.br

* M estre em Educação pela Universidade Federal de Santa Catarina (UFSC). E-mail: klalter@yahoo.com.br 
First, the study results are briefly presented, and then an analysis of the production on teachers' work is developed in the light of the $M$ arxist framework. For such, a study of the meaning of labor in capitalism and the distinctions between work processes and capital production processes is carried out, as well as a study of the conception of work producing capital. This basis has allowed a discussion on the relation between teachers as workers and the social classes, which, in its turn, leads to the discussion of the role of teachers, not only as teachers, but also as a class, in the process of revolutionary transformation of capitalism.

Key words: Teachers' work. C apitalism. Working class.

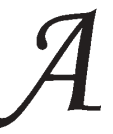

s investigações sobre 0 trabal ho docente, em sua inter-relação com outras categorias profissionais, começaram a emergir como objeto de estudo na pesquisa educacional brasileira no final da década de 1970 (O liveira, 2003), tendo como temas centrais a organização do trabalho docente e a gestão da escola. Essas duas temáticas abriram espaço para as discussões sobre a profissionalização e a proletarização docentes, a organização escolar e a feminização do magistério (H ypólito, 1994; O liveira, 2003).

No final da década de 1980 as pesquisas sobre o trabalho docente foram se deslocando das relações de trabal ho na escola para os estudos sobre os aspectos culturais e a formação docente, em consonância com 0 período em que as reformas educacionais enfatizavam a necessidade de um novo professor, com habilidades e competências necessárias para atender aos objetivos requeridos pelo mercado. As pesquisas sobre a natureza do trabalho docente, a teoria da mais-valia e sua aplicabilidade ou não nas escolas, o caráter produtivo ou improdutivo do trabalho escolar, a suposta autonomia e/ou alienação do docente foram sendo substituídas por estudos que priorizaram as relações de gênero, cultura escolar e formação docente (H ypólito, 1994).

0 presente texto pretende apresentar, de forma resumida, dados os limites postos, um balanço e uma análise da produção investigativa sobre o trabalho docente da década de 1990 no Brasil, identificando as principais concepções e o tratamento analítico desenvolvido pelos pesquisadores que apreciaram o referido tema, dando destaque para a questão da proletarização docente. N um primeiro momento, exporemos, de 
maneira sucinta, os resultados que obtivemos a partir de nosso estudo, para depois desenvolvermos uma análise daquela produção à luz do referencial marxista.

Trabalho docente e proletarização na produção acadêmica da década de 1990

Para a efetivação de nosso estudo, realizamos, num primeiro momento, um levantamento detalhado da produção acadêmica sobre o trabalho docente na década de 1990, totalizando 120 textos, $^{1}$ e, em seguida, selecionamos criteriosamente 39 publicações, assim distribuídas: 3 teses, 15 dissertações, 11 artigos e 10 livros. $^{2}$ A leitura dessa produção possibilitou mapear as concepções que nortearam cada pesquisa e os pressupostos teóricos que subsidiaram as análises dos investigadores. Essa identificação foi essencial para verificar a compreensão dos pesquisadores sobre 0 trabalho docente e suas especificidades, possibilitando a construção de um quadro geral em relação ao estudo do trabalho docente que caracterizou o período.

$\mathrm{N}$ as pesquisas analisadas, a discussão sobre a proletarização docente está diretamente vinculada aos estudos sobre o processo de profissionalização dos docentes. O bservamos que os autores identificam a proletarização como um processo antagônico à profissionalização do magistério, e é a partir dessa ambivalência que os estudos foram desenvolvidos. Por isso, entre os vários temas abordados, destacaremos, neste artigo, as pesquisas que investigaram o trabalho docente e seu processo de proletarização, a partir das discussões sobre a feminização do magistério, a (re)organização escolar e a atividade docente, a organização de "classe" 3 e o docente como trabalhador produtivo, considerando na análise a relação antagônica entre a profissionalização e a proletarização docente, estabelecida pelos pesquisadores. ${ }^{4}$

A relação entre a feminização e a proletarização docente foi significativa em algumas pesquisas. Tito (1994), Costa (1995) e Carvalho (1996) destacaram a importância de se resgatar o debate sobre gênero na constituição do magistério e sua relação com o processo de proletarização. Para esses pesquisadores, a entrada massiva da mulher no magistério provocou no imaginário social e na constituição profissional da categoria uma crescente desvalorização social e salarial. 0 vínculo entre a 
Trabalho docente e capitalismo: um estudo crítico da produção acadêmica...

docência, as atividades domésticas e o aspecto vocacional atribuíram ao trabalho docente uma conotação servil e dócil, que o diferenciou das atividades exercidas por outras categorias de trabalhadores. 0 s pesquisadores afirmam que esses aspectos, em geral atribuídos ao professor de séries iniciais, tornam este trabalhador mais suscetível ao processo de proletarização do que, por exemplo, o professor universitário, que continua gozando de prestígio social e reconhecimento profissional.

0 utro aspecto evidenciado nas pesquisas é a proletarização como resultado das mudanças provocadas na organização escolar e na atividade docente na atual conjuntura do capital. N ajjar (1992), N unes (1998) e Therrien (1998) salientam que o professor vem sofrendo um processo de proletarização que 0 assemelha ao trabalhador fabril. ${ }^{5} \mathrm{~A}$ crescente desqualificação e fragmentação do seu trabalho, a "popularização" do ato de ensinar, o desprestígio social da ocupação, a baixa remuneração e a presença dos especialistas na escola são fatores que induzem a categoria à sua proletarização. N esses trabalhos, a proletarização é analisada a partir das implicações do capitalismo sobre as especificidades do trabalho do professor em seu fazer pedagógico, e as conseqüências deste movimento na autonomia e no controle do professor em relação ao seu trabalho. O s autores afirmam ainda que o docente, mesmo sofrendo um processo de proletarização que o assemelha ao trabalhador fabril, deve ser analisado de forma diferenciada, pois não é um trabalhador submetido à lógica capitalista.

0 movimento de "classe" aparece em algumas pesquisas (Beckenkamp, 2000; Lugli, 1997; Polettini, 1998; Vianna, 1999) como um dos elementos centrai $s^{6}$ para a compreensão da proletarização docente e a necessidade de conscientização do professor como um trabalhador inserido no sistema capitalista. N essas pesquisas, a organização do magistério mostra-se como uma ferramenta necessária ao professor para reivindicar melhores condições salariais e de trabal ho. Para Beckenkamp (2000), 0 processo de empobrecimento gradativo e sistemático do professorado e a falta de motivação profissional desses trabalhadores são algo inerente à sua proletarização.

A discussão sobre o docente ser um trabalhador produtivo ou não aparece de forma incipiente em algumas poucas pesquisas que foram realizadas no início da década de 1990. H ypólito (1994), N unes (1990) e Wenzel (1991) discutem o trabalho docente a partir de uma análise 
sobre a natureza desse trabal ho na sociedade capitalista, e, por isso, oferecem uma acuidade teórica sobre o trabalho produtivo e a proletarização que vai além da análise das demais pesquisas apreciadas.

H ypólito (1994) afirma ser a proletarização um processo de assalariamento e precarização profissional ao qual está submetido um grande número de trabalhadores. Já para Wenzel (1991), a proletarização é resultado da produção capitalista que retira do trabalhador o controle sobre o processo produtivo. Trabalhador proletário é a negação do trabalhador individual e a afirmação do trabalhador coletivo. $\mathrm{N}$ a análise desses pesquisadores, o docente é proletário na medida em que sofre um processo de precarização e assalariamento e se afirma como um trabalhador coletivo.

Em relação ao trabalho produtivo, $\mathrm{N}$ unes (1990) apresenta o docente como trabalhador produtivo na medida em que se encontra numa relação social no interior da organização do trabalho que o faz produzir mais-valia. Para a pesquisadora, o proletariado é o produtor da mais-valia, sendo esta o resultado do sobretrabalho que é produzido pelo trabalhador. Apesar da análise rigorosa acerca do trabal ho produtivo, a pesquisadora afirma que os gestores escolares não são considerados trabalhadores produtivos, pois constituem uma "classe" diferenciada em comparação com os professores em docência.

É importante sublinhar que praticamente todos os pesquisadores com quem dialogamos se referenciaram em Enguita (1991), que busca compreender a natureza do trabalho docente começando por apresentar e diferenciar os profissionais e os proletários. O s primeiros, que se caracterizam por um conjunto de aspectos, afirmam sua autonomia e seu controle sobre o seu processo de trabalho, apesar das imposições postas nas relações capitalistas, e os proletários, entendidos como trabalhadores assalariados, são aqueles desprovidos dos meios de produção e partícipes essenciais na produção e reprodução do capital, os quais, dessa forma, perdem o controle sobre os meios, o objetivo e o processo de trabalho. ${ }^{7}$

$\mathrm{N}$ a relação antagônica entre profissionais e proletários, Enguita apresenta os semiprofissionais, uma categoria de trabalhadores que permanece numa posição intermediária, por apresentar aspectos de ambas as "classes". Para ele, os semiprofissionais

(...) constituem o que no jargão sociológico se designa como semiprofissões, geralmente constituídas por grupos assal ariados, amiúde parte de burocracias 
públicas, cujo nível deformação ésimilar ao dos profissionaisliberais. G rupos que estão submetidosà autoridade de seus empregadores mas que lutam por manter ou ampliar sua autonomia no processo detrabal ho esuas vantagens re lativas quanto à distribuição da renda, ao poder eao prestígio. U m destesgruposéo constituído pel os docentes (Enguita, 1991, p. 43; sem grifos no original)

A urbanização e a expansão do ensino público e privado, e a conse qüente hierarquização da organização escolar, com a figura do diretor e dos especialistas educacionais, resultaram numa redução da autonomia docente no processo educacional. A padronização dos programas de ensino e dos currículos escolares contribuiu para uma diminuição na participação do professor no resultado do seu trabalho, já que estas regulamentações influenciam no conteúdo que o professor deve ensinar e em como ele irá ensinar. Este processo resulta, na análise de Enguita (1991), numa aproximação dos docentes aos proletários, embora a qualificação requerida para 0 desenvolvimento de sua atividade e a conservação, em grande parte, do controle sobre o seu processo de trabalho os coloquem próximos dos profissionais. Assim, os docentes encontram-se neste lugar intermediário, nesta ambivalência entre a profissionalização e a proletarização, chamado das semiprofissões.

Após o estudo dessas pesquisas, é possível constatar que a proletarização é percebida como um processo inerente à desqualificação e precarização do trabalho docente, em decorrência das mudanças ocorridas na sociedade capitalista e, como conseqüência, no processo de trabalho do professor. Ao contrário da proletarização, a profissionalização é afirmada como um movimento que promove a categoria do magistério à consolidação desses trabaIhadores como profissionais. Além disso, nota-se que as explicações que os autores ofereceram sobre trabalho produtivo e proletarização docente são bastante díspares e, em alguns casos, acentuadamente divergentes. Isso se deve não ao foco que deram ao tema eleito, mas, possivelmente, à escolha de referenciais teóricos também distintos que foram utilizados para analisar 0 trabalho docente. Percebe-se, por exemplo, que, embora o referencial marxista tenha sido resgatado nas pesquisas no início dos anos de 1990, seu uso foi sendo negligenciado pelos pesquisadores ao longo do período, uma vez que, para muitos deles, as categorias marxistas não eram adequadas para a compreensão das especificidades do trabalho docente.

0 que mais chamou a atenção, contudo, é o fato de que os pesquisadores em geral tenham restringido suas análises do trabal ho docente ao 
processo de trabalho, sem levar na devida consideração a relação com o processo de produção capitalista. M esmo aqueles poucos que buscaram fazer tal relação apresentam alguns problemas e limites. É o que procuraremos discutir a seguir.

\section{As "naturezas" do trabalho docente no capitalismo}

Para que possamos dialogar analiticamente com os resultados da produção acadêmica sobre o trabalho docente na década de 1990, parece-nos necessário apresentar nossa compreensão acerca da natureza desse trabalho.

0 trabalho, numa forma social genérica, pode ser compreendido como a utilização da força de trabalho, na relação com a natureza, para a produção de valores de uso necessários à vida humana. D essa forma, o processo simples de trabalho é condição sine qua non para a produção da existência do ser social, independentemente do modo de produção existente. Entretanto, já que no capitalismo o processo de trabalho se encontra subsumido à lógica do capital, é preciso compreender e distinguir processo de trabalho e processo de produção capitalista. N o capítulo $\mathrm{V}$ de $\mathrm{O}$ capital, $\mathrm{M}$ arx define o processo de trabalho como uma

(...) atividade orientada a um fim para produzir valores de uso, apropriação do natural para satisfazer as necessidades humanas, condição universal do metabolismo entre o homem ea $\mathrm{N}$ atureza, condição natural eterna da vida humana e, portanto, independente de qualquer forma dessa vida, sendo antes igualmente comum a todas as suas formas sociais. ( $M$ arx, 1983, p. 153)

$\mathrm{N}$ a seqüência do mesmo capítulo, $\mathrm{M}$ arx apresenta e analisa o processo de formação do valor e o processo de valorização, distinguindo-os entre eles, e o processo simples de trabalho. A esse respeito, Tumolo afirma que,

(...) depois de ressaltar as especificidades e distinções entre os três processos, o autor busca estabelecer conexões entre eles, compreendendo o processo de produção de mercadorias como unidade entre processo de trabalho e processo de formação de val or e, diferentemente, o processo de produção capitalista, forma capitalista da produção de mercadorias, como unidade do processo de trabalho edo processo de valorização. Esteúltimo, cujo escopo é a produção 
Trabalho docente e capitalismo: um estudo crítico da produção acadêmica...

de capital, distingue-se do anterior, que tem como finalidade a produção apenas demercadorias. Ambos se diferenciam do processo simples detrabaIho, uma vez que este objetiva a produção somente de valor de uso, de riqueza e, por isso, não pressupõe nenhum dos outros dois processos. 0 processo de produção de mercadorias implica o processo detrabalho, masnão o processo de produção capitalista, e este, por sua vez, pressupõe os outros dois processos. (Tumolo, 2005, p. 250; grifos do autor)

0 processo simples de trabalho resulta na produção de valores de uso para satisfação de necessidades humanas, ao passo que o processo de produção capitalista - que pressupõe o processo de trabalho - tem como finalidade a produção de mais-valia e, fundamentalmente, de capital. Somente a partir dessas compreensões e distinções é que se pode apreender o conceito de trabalho produtivo. Para M arx, trabalho produtivo é aquele referente ao processo de produção capitalista, ou seja, é trabalho que produz mais-valia e, conseqüentemente, capital. ${ }^{8} 0$ autor afirma que

(...) a produção capitalista não é apenas produção de mercadoria, é essencialmente produção de mais-valia. 0 trabalhador produz não parasi, mas para o capital. N ão basta, portanto, que produza em geral. Ele tem de produzir mais-valia. A penas é produtivo o trabalhador que produz mais-valia para o capital ista ou serve à autovalorização do capital. (...) 0 conceito de trabal ho produtivo, portanto, não encerra de modo algum apenas uma relação entrea atividade e ef eito útil, entre trabal hador e produto do trabaIho, mas também uma relação de produção especificamente social, formada historicamente, a qual marca o trabal hador como meio direto de val orização do capital. Ser trabal hador produtivo não é, portanto, sorte, mas azar. (M arx, 1984, p. 105 e 106)

0 conceito de trabalho produtivo, portanto, não se refere aos aspectos concernentes ao trabal ho concreto - trabalho do metalúrgico, do camponês, do palhaço, do professor, do homem, da mulher, trabalho manual ou intelectual etc. - , ou às características do valor de uso que foi produzido - se tem ou não uma "forma corpórea", se é automóvel, arroz, entretenimento, ensino etc. -, se serve para satisfazer esta ou aquela necessidade - do estômago ou da fantasia. Também não diz respeito aos setores de atividade econômica: primário, secundário ou terciário, como é o caso do setor de serviços. Esses elementos, pertencentes ao processo de trabalho, não permitem, em absoluto, a compreensão de trabalho produtivo, uma vez que este é, necessariamente, trabalho referente ao processo de produção de capital. Isso significa dizer que o trabalho produtivo está 
presente em toda e qualquer relação de produção capitalista, não importando se se trata de uma empresa agrícola, fabril ou uma empresa escolar, se a mercadoria produzida é soja, robô ou ensino.

A partir dessa base conceitual é que podemos apreender, nos seus fundamentos, o trabalho docente, tanto do ponto de vista do processo de trabalho como, sobretudo, da perspectiva das relações sociais de produção e do processo de produção capitalista.

Atualmente, os trabalhadores da educação são constituídos, em sua maioria, por trabalhadores assalariados, seja no sistema público ou privado de ensino. Por estabelecerem uma relação contratual baseada no assalariamento, apresentam uma relação similar àquelas estabelecidas por outros trabalhadores assalariados, já que a natureza da relação é a mesma. Entretanto, nem todo trabalhador assalariado é produtor de capital, apesar de todo trabalhador produtivo ser assalariado. I sso quer dizer que existem trabaIhadores assalariados, incluindo aqui professores, que estabelecem e outros que não estabelecem a relação de produção especificamente capitalista, ou seja, que são ou não produtivos. Além disso, também existem professores que exercem sua atividade sem ser assalariados e, neste caso, não são produtivos. Apesar de desempenharem o mesmo trabalho concreto, quer dizer, de executarem o mesmo processo de trabalho, os trabalhadores docentes apontados anteriormente participam de relações sociais de produção diferentes.

Para oferecer subsídios a essa discussão, apresentamos a seguir quatro situações ilustrativas de "trabal hos docentes" que existem no capitalismo para que se possa verificar as relações de produção nas quais os trabalhadores docentes estão inseridos. ${ }^{9}$

Encontramos primeiramente a docência como um processo simples de trabalho, como, por exemplo, o professor que ensina seu filho a ler. Trata-se da produção de um valor de uso e não de uma mercadoria e, por isso, não houve produção de valor nem de mais-valia, o que caracteriza esse professor como um trabalhador não-produtivo.

0 utra situação é o professor que produz o ensino como um valor de troca, ou seja, como uma mercadoria que vende, como, por exemplo, um professor que ministra aulas particulares. Embora tenha produzido vaIor, não produziu mais-valia, uma vez que, sendo proprietário de meios de produção, não necessitou vender sua força de trabalho e, por isso, não estabeleceu uma relação assalariada, constituindo-se também como um trabalhador não-produtivo. 
Trabalho docente e capitalismo: um estudo crítico da produção acadêmica...

N uma condição totalmente diferenciada, temos o professor que trabalha na rede privada de ensino. N essa situação, o professor vende sua força de trabalho ao proprietário da escola, produz uma mercadoria ensino - , que pertence a este último, e, ao fazêlo, produz mais-valia e, conseqüentemente, capital, o que o caracteriza como um trabalhador produtivo. Sobre isso, M arx esclarece:

Sefor permitido escolher um exemplo fora da esfera da produção material, então um mestre-escola é um trabalhador produtivo se ele não apenas trabalha as cabeças das crianças, mas extenua a si mesmo para enriquecer 0 empresário. 0 fato de que esteúltimo tenha investido seu capital numa fábrica de ensinar, em vez de numa fábrica de salsichas, não altera nada na relação (M arx, 1984, p. 105-106).

Embora estejamos considerando que nem todas as escolas privadas se constituem como empresas capitalistas, ou seja, que existem escolas privadas nas quais não ocorre a relação de produção especificamente capitalista, é necessário reconhecer, de outro lado, que as primeiras são claramente determinantes em relação a estas últimas. Por isso, neste texto, quando mencionarmos escola privada estaremos nos referindo àquelas escolas nas quais se realiza a produção de capital, confirmando o caráter produtivo do trabalho do professor.

N uma última situação, o professor de escola pública. Em nossa compreensão, embora venda sua força de trabalho ao Estado, ele produz um valor de uso e não um valor de troca e, portanto, não produz valor nem mais-valia. Como não estabeleceu a relação especificamente capitalista, não pode ser considerado um trabalhador produtivo. ${ }^{10}$

Partindo do princípio de que todos os trabalhadores docentes estejam submetidos à lógica capitalista, pois vivemos numa sociedade determinada por esta forma social, essas quatro situações ilustrativas do trabalho docente demonstram que todos esses professores, apesar de terem exatamente a mesma identidade no que se refere ao trabalho concreto o trabalho de ensinar - , ou seja, executarem o mesmo processo de trabaIho e produzirem o mesmo produto, estabeleceram relações de produção completamente distintas. 0 primeiro produziu apenas um valor de uso para si (para sua família), o segundo produziu uma mercadoria de sua propriedade, porque lhe pertencem os meios de produção, e a vendeu. Ambos não participaram de nenhuma relação assalariada, ao contrário dos últimos dois. 0 terceiro estabeleceu a relação de produção 
especificamente capitalista, na medida em que vendeu sua força de trabalho para o proprietário da empresa escolar e, dessa forma, produziu mais-valia e, conseqüentemente, capital. Aqui se cumpriu a exploração especificamente capitalista. 0 quarto, apesar de ser também vendedor da força de trabalho, participou de uma relação de produção na qual não existe a produção de valor, de mais-valia e de capital. Embora estes últimos tenham estabelecido relações assalariadas, elas são de naturezas distintas. D os quatro casos, apenas o terceiro é um trabalhador produtivo, embora considerando que todos produziram o mesmo valor de uso, 0 ensino. Supondo, para afinar ainda mais a análise, que nos quatro exemplos os docentes sejam professores de língua portuguesa, que trabalhem com alunos da mesma série escolar e valendo-se dos mesmos procedimentos didático-metodológicos, do ponto de vista do processo de trabaIho não há nenhuma distinção entre os quatro trabalhos docentes, mas, ao contrário, como já afirmado, há uma total identificação. Contudo, do ponto de vista das relações de produção, estas são de naturezas totalmente diferentes, sendo que somente o terceiro estava inserido no processo de produção de capital, o que o caracteriza como trabalhador produtivo.

\section{Trabalho docente e classe proletária}

Considerando o processo de trabalho - ou se se quiser, o trabalho concreto - , o trabalho docente tem, de fato, suas especificidades e se diferencia do trabalho de outros profissionais, que, no seu conjunto, constituem as chamadas categorias profissionais. N este âmbito, os professores têm uma única identidade: ser professor. 0 que pudemos constatar, ao apreciarmos a produção dos anos de 1990 sobre o trabalho docente, é que a imensa maioria dos pesquisadores tratou deste assunto justamente sob esse prisma, sobretudo aqueles que apontaram a tendência de proletarização do trabalhador docente. Como já foi visto anteriormente, tais autores consideram o processo de proletarização do professor resultado da precarização de suas condições de trabalho, do rebaixamento salarial, de sua desqualificação, da perda do controle do processo de trabaIho, do desprestígio social da ocupação etc. Por essa razão, quase todos não fizeram a diferenciação entre professores que trabalham em escolas públicas e os que trabalham em escolas privadas. No fundo, eles compreendem a conversão dos professores em proletários no plano do processo de trabalho. D aí, a associação, que vários autores fizeram, entre o 
Trabalho docente e capitalismo: um estudo crítico da produção acadêmica...

trabalho fabril e o trabalho docente, que foi gradativamente incorporando as características do primeiro, um trabalho taylorizado, padronizado, repetitivo, fragmentado etc. Como, explícita ou implicitamente, identificam proletário com operário fabril e como têm evidenciado as profundas similaridades entre 0 trabalho fabril e o trabalho docente em grande parte dos casos, concluem que os professores têm se transformado em proletários.

O ra, em nossa perspectiva analítica, é impossível apreender classe proletária no âmbito do processo de trabalho. Embora tenhamos plena clareza de que a discussão sobre classe social é deveras difícil, complexa e polêmica no interior do marxismo, não encontrando aqui nenhum consenso, fomos instigados, pelas posições defendidas pelos pesquisadores que estudamos, a oferecer nossa contribuição, tendo ciência de seus limites e precariedades.

0 primeiro aspecto que gostaríamos de sublinhar é o fato de que classe social não é um conceito estático, assim como o de capital, daí a importância de tratá-lo no movimento contraditório do capital. D e outra parte, seria, no mínimo, problemático discutir classe social sem levar em conta a questão da consciência de classe. Contudo, como é impossível nos marcos deste texto abordar, de forma satisfatória, o conceito de classe social na sua totalidade, concentrar-nos-emos nos elementos constitutivos da base material, ou melhor, naqueles referentes às relações sociais de produção, destacando aqueles que são pertinentes ao nosso objeto específico de estudo: o trabalhador docente.

Em nossa compreensão, o proletariado não pode ser apreendido a partir das características concernentes ao processo de trabalho, mas sim com base na relação social de produção. Assim, do ponto de vista da "classe em si", proletariado é a classe social antagônica à classe capitalista, que, desprovida da propriedade de qualquer meio de produção, vende sua força de trabalho para aquela classe e que, ao produzir uma mercadoria, produz valor, mais-valia e capital. O u seja, é a classe que, juntamente com a classe capitalista, compõe a relação de produção especificamente capitalista. Tal compreensão independe do tipo de trabalho concreto que é realizado, das características do valor de uso produzido e do setor de atividade econômica - um trabalhador do setor primário (campo) que produz maçã, um do setor secundário (industrial urbano) que fabrica máquinas ou um do setor terciário (serviço) que produz ensino. 
Também não tem nada que ver com as condições de trabalho, com 0 nível salarial, com características do trabalho - trabalho manual, trabaIho intelectual, trabalho padronizado ou não, repetitivo ou não, trabaIho menos ou mais qualificado etc. $\mathrm{N}$ ada disso importa, porque tudo isso diz respeito ao processo de trabalho. 0 conceito de classe proletária supera, pois, todos esses aspectos porque sua base é a relação de produção especificamente capitalista.

Acerca do trabalhador docente, se tomarmos as quatro situações elencadas anteriormente, consideramos que somente aquele do terceiro exemplo se constitui como proletário, ${ }^{11}$ porque é o único que participa da relação de produção capitalista. O s dois primeiros não o são já que nem são vendedores de força de trabalho. 0 quarto, professor de escola pública, apesar de ser vendedor da força de trabalho, não estabelece a relação especificamente capitalista. ${ }^{12}$ Contudo, ele, o terceiro, não é proletário porque é professor, e muito menos porque suas condições de trabalho podem estar deterioradas, seu salário rebaixado, ou porque seu trabalho pode ser padronizado, repetitivo, fragmentado e enfadonho tal qual como pode acontecer com o operário fabril, ou ainda porque há uma desqualificação de sua força de trabalho e uma perda do controle de seu trabalho ou de prestígio social, mas porque, independentemente das características do processo de trabalho, é um trabalhador inserido num processo de produção de capital. Como proletário, ele "deixa de ser" professor, "deixa de ser" categoria profissional de professores e "passa a ser" classe: classe proletária. Como classe proletária, o professor não se distingue dos outros trabal hadores proletários - exemplo: cortador de cana-de-açúcar, metalúrgico, programador de sistemas etc. - que estabelecem a relação capitalista de produção e produzem capital. Todos eles são um só, e a mesma coisa: classe proletária. Como classe, são uma unidade. N essa perspectiva, do processo de produção do capital, a unidade ocorre entre a diversidade dos processos de trabalho e de trabalhos concretos, ou seja, trabal hadores que exercem os mais variados trabalhos, com características tão diferenciadoras como é o caso de um professor e um cortador de cana, de ramos de atividades tão distintos, são a mesma classe. Em contrapartida, o professor que trabalha numa empresa capitalista de ensino tem uma identidade com os professores das outras três situações, uma vez que, sob o ponto de vista do processo de trabalho, executam o mesmo trabalho concreto - ser professor - e, neste plano, pertencem à mesma categoria profissional. Trata-se, aqui, da unidade do processo de trabalho e do trabalho concreto na diversidade das 
Trabalho docente e capitalismo: um estudo crítico da produção acadêmica...

relações de produção. Porém, da ótica do processo de produção de capital, ou melhor, das relações sociais de produção, eles são significativamente distintos. 0 s dois primeiros não são proletários porque nem são vendedores de força de trabalho, o professor de escola pública, apesar de ser vendedor da força de trabalho, em nossa compreensão, também não o é, sendo que somente o terceiro é proletário. Este último encontra sua identidade, como classe, com os "outros" trabalhadores proletários, e não com seus companheiros trabalhadores docentes vinculados a outras relações de produção que não a capitalista.

\section{Considerações finais}

Conforme já havíamos afirmado anteriormente, os autores que pesquisaram o trabalho docente na década de 1990, na sua quase totalidade, fizeram-no restringindo suas análises ao processo de trabalho. M esmo aqueles que buscaram uma superação dessa restrição, como, por exemplo, H ypólito (1994), N unes (1990) e Wenzel (1991), apresentaram problemas, limites e insuficiências. 0 caso mais emblemático, contudo, parece ser o de Enguita (1991), que serviu, de uma forma ou de outra, como referência para quase todos os investigadores. Como já salientamos, este autor faz uma diferenciação entre proletários, profissionais e semiprofissionais e inclui os docentes nesta última classificação. Suas posições mereceriam uma análise mais detalhada e aprofundada do que é possível fazer aqui. Contudo, é fundamental destacar que, a partir de nossa perspectiva analítica, profissionais (e também semiprofissionais) e proletários são duas compreensões de planos analíticos e políticos distintos. Ele não percebeu que a discussão sobre profissionais, ou categoria profissional, é referente ao processo de trabal ho e que a de proletário diz respeito ao processo de produção de capital. D essa forma, a compreensão de proletarização como antagônica à de profissionalização, defendida por Enguita e incorporada na análise de quase todos os outros autores, fica sem sentido. N o fundo, Enguita também não diferencia processo de trabalho e processo de produção e, por isso, confunde categoria profissional com classe social. O ra, professores que têm, parcial ou totalmente, características de "profissionais ou semiprofissionais" podem ser ou não proletários. Esta condição de classe não depende, como vimos, de tais características, mas sim da relação social de produção na qual o professor esteja inserido. 
A insistência de termos salientado que os investigadores que foram apreciados por nós, em sua grande maioria, restringiram suas análises ao processo de trabalho e não fizeram, satisfatoriamente, a distinção com o processo de produção de capital tem uma razão principal: tal forma de abordar o tema tem implicações na compreensão de classe social. A nosso ver, o desenvolvimento de seus argumentos a este respeito evidencia compreensões limitadas, problemáticas ou equivocadas. Por causa disso, não conseguem perceber com clareza a composição de classes das quais os docentes "fazem parte" e, principalmente, as tendências dessa composição.

Entre as quatro situações ilustrativas de trabalhos docentes apresentadas anteriormente, vimos que a imensa maioria dos professores no capitalismo contemporâneo, inclusive no Brasil, é constituída por assalariados. As duas primeiras situações, a do professor que produz valor de uso e a daquele que produz mercadoria de sua propriedade e a vende, existem e continuarão a existir; mas, objetivamente, de forma secundarizada e periférica. 0 que se impôs para os docentes, como de resto para 0 conjunto dos trabalhadores, foi a determinação da relação assalariada. Contudo, como já foi sublinhado, no interior desta há os professores que são trabalhadores do Estado capitalista e aqueles que vendem a força de trabal ho para empresas capitalistas de ensino, os quais nós consideramos proletários. 0 que se tem observado nos períodos mais recentes no Brasil é uma tendência de crescimento relativo dos docentes que estabelecem a re lação capitalista, quando se compara com aqueles que são trabalhadores do Estado, o que significa dizer que há uma tendência de crescimento de professores proletários em relação aos outros.

A pesquisa INEP/MEC (2004) mostra que o número de docentes que lecionavam em escolas públicas cresceu 32,35\% entre os anos de 1991 e 2002 e que 0 daqueles que trabalhavam em escolas particulares teve um aumento de $41,21 \%$, evidenciando fenômenos que tendem a crescer: a mercantilização do ensino e a conseqüente proletarização dos professores. Entretanto, o caso mais gritante é o do ensino superior. 0 utra pesquisa realizada pelo IN EP/M EC (2003) demonstra que, em 1997, o Brasil tinha 211 escolas de nível superior públicas e 689 escolas superiores privadas. Pouco tempo depois, em junho de 2003, a rede pública mantinha quase o mesmo número, contando com 207 instituições de ensino superior com um total de 95.863 professores. Em contraste, a rede privada contava com 1.652 instituições e com 172.953 professores. Tais números revelam não 
Trabalho docente e capitalismo: um estudo crítico da produção acadêmica...

apenas a existência de professores proletários no ensino superior, como, principalmente, que eles somam $80 \%$ a mais que o número dos não-proletários, ou seja, quase 0 dobro.

Como demonstram os dados, a proletarização docente vem crescendo em termos absolutos e relativos em todos os níveis de ensino, mas principalmente no ensino superior. Contudo, insistimos: a proletarização dos docentes não ocorre por causa das características do processo de trabalho, como defenderam os autores que investigaram o trabalho docente. Se a argumentação aqui apresentada é estranha a eles no que se refere aos professores em geral, muito mais ainda o é em relação aos professores do ensino superior, uma vez que chegamos à conclusão de que a maioria deles é de proletários. Tal conclusão soaria como um absurdo dentro de suas construções teóricas, já que, como suas análises se restringiram ao processo de trabaIho ou não conseguiram estabelecer uma articulação satisfatória deste com o processo de produção capitalista, não fizeram a diferenciação entre professores de escola pública e de escola privada, partícipes de relações sociais de produção distintas que determinam, por sua vez, diferentes inserções de classe.

N osso propósito, ao apontarmos os limites analíticos da produção acadêmica sobre o trabalho docente na década de 1990, foi o de trazer à tona a questão da relação entre os trabalhadores docentes e as classes sociais, o que reabre a discussão sobre o papel dos professores, não apenas como professores, mas sobretudo como classe, no processo de transformação revolucionária do capitalismo. N ão como "classe-em-si", mas como "classe-para-si", classe revolucionária, síntese histórica de todas as classes e segmentos sociais que se contrapõem ao sistema sociometabólico do capital.

Recebido em março de 2007 e aprovado em outubro de 2007.

\section{$\mathrm{N}$ otas}

1. O levantamento foi feito nas seguintes bases: 1) acesso ao banco de dados na plataforma da CAPES e do cN Pq (http://www.capes.org.br e http://www.cnpq.br), no período de outubro de 2003 a abril de 2004, que forneceu, sobretudo, a produção referente às teses e dissertações; 2) livros; 3) artigos publicados nas principais revistas especializadas em educação, principalmente nas revistas Educação \& Sociedade; Cadernos Ced Es; Perspectiva; Trabalho \& Educação; Teoria \& Educação; Re vista Brasileira de Educação (consultando, inclusive, os arquivos on-line dessas revistas); 4) textos disponíveis digitalmente da produção sobre trabalho docente da AN PEd; 5) consultas em bibliotecas universitárias, livrarias e nas próprias referências bibliográficas dos textos.

2. Foram selecionados os textos pertinentes ao tema e aos objetivos da pesquisa, os que se mostraram ser as referências principais entre o conjunto de autores e aqueles que expressavam a 
representatividade do autor e do texto em relação à produção da década (havia textos, de diferentes autores, em que o tratamento analítico era similar e textos praticamente repetitivos de um mesmo autor - por exemplo, um trabalho apresentado em evento que era resultado de dissertação ou tese). Tomando o conjunto da produção levantada, a seleção foi feita por meio da leitura dos resumos, no caso de teses, dissertações, artigos e textos apresentados em evento, e da leitura de prefácio e/ou introdução, sumário, orelha e quarta capa, no caso dos livros.

3. Esta expressão é utilizada pelos pesquisadores e será usada por nós entre aspas, por razões que serão apresentadas posteriormente.

4. O s textos aqui analisados, e referidos no decorrer do presente artigo, refletem, de maneira geral, a concepção de trabalho docente presente na totalidade das pesquisas investigadas em nosso trabalho. Ademais, os autores desses textos se destacam por serem utilizados também como referência pelos demais autores em suas investigações.

5. N essas pesquisas, o termo "trabalhadores proletários" é utilizado numa conotação similar à de trabalhadores fabris.

6. Embora nessas pesquisas também se encontrem referências à feminização do magistério e ao processo de desqualificação do trabalho docente, a ênfase na análise sobre a proletarização é dada a partir da organização dos trabalhadores.

7. Para uma melhor compreensão, vide o próprio autor (Enguita, 1991). Suas posições exerceram uma grande influência nos investigadores do trabalho docente e, por isso, mereceriam uma análise mais detalhada e aprofundada, que escapa aos limites deste texto.

8. Além de 0 capital, M arx trata desse mesmo tema em outros textos, tais como Capítulo VI iné dito de 0 capital e Teorias da mais-valia. Também outros autores, como, por exemplo, Rubin (1987), discutem esse assunto. É preciso sublinhar, entretanto, que a concepção aqui arrolada de trabalho produtivo não é consensual no âmbito do marxismo.

9. É necessário fazer um alerta: os casos que apresentamos servem apenas como exemplos ilustrativos e foram tomados como instrumentos para facilitar a compreensão, uma vez que, a rigor, um trabalhador individual ou uma categoria de trabalhadores não podem ser produtivos, pela simples razão de que o trabalhador produtivo de capital é necessariamente 0 trabalhador social.

10. É importante destacar que esta compreensão do professor de escola pública como não-produtivo é polêmica, mesmo entre pesquisadores marxistas.

11. N ovamente cabe, aqui, um esclarecimento: somente é proletário o professor que vende sua força de trabalho para uma empresa escolar capitalista e não para uma escola particular nãocapitalista.

12. Como já havíamos sublinhado anteriormente, tais compreensões não são consensuais. Há pensadores que entendem que todo e qualquer vendedor da força de trabalho é proletário. N esta acepção, o professor de escola pública também seria proletário.

\section{Referências}
ABD ALLA, M.F.B. Formação e desenvolvimento profissional do professor: 0 aprender da profissão (um estudo em escola pública). 2000. Tese (D ou- torado) - Universidade de São Paulo, São Paulo.

Educ. Soc., Campinas, vol. 29, n. 102, p. 159-180, jan./abr. 2008

Disponível em বttp://www.cedes.unicamp.br> 
Trabalho docente e capitalismo: um estudo crítico da produção acadêmica...

ALM EID A, M .I. Perfil dos professores da escola pública paulista. 1991. D issertação (M estrado) - Universidade de São Paulo, São Paulo.

ANTUNES, R. Adeus ao trabalho?: ensaio sobre as metamorfoses e a centralidade do mundo do trabalho. 8. ed. São Paulo: Cortez, 2002.

ANTUN ES, R. Os sentidos do trabalho. 2. ed. São Paulo: Boitempo, 2003.

AZZI, S. D a autonomia negada à autonomia possivel: trabalho docente na escola pública capitalista - um estudo a partir da sala de aula. 1994. Tese (D outorado) - Universidade de São Paulo, São Paulo.

BASSO I.S. Significado e sentido do trabalho docente. Cadernos CEDES, Campinas, v. 19, n. 44, p. 19-32, abr. 1998.

BECKEN KAM P, A.H . Empobrecimento e futuro do trabalho docente na visão de professoras do ensino fundamental da rede pública estadual do Estado do Rio Grande do Sul. 2000. Dissertação (M estrado) - Universidade Federal de Pelotas, Pelotas.

BRAN DÃO, C.R. (O rg.). 0 educador: vida e morte. 10. ed. Rio de Janeiro: Graal, 1992.

BRASIL. M inistério da Educação. Instituto N acional de Estudos e Pesquisas Educacionais (In EP). Censo do Ensino Superior. 2003. Disponível em: 〈http://www.inep.gov.br/superior/censosuperior/sinopse>. Acesso em: 23 mar. 2005.

BRASIL. M inistério da Educação. Instituto N acional de Estudos e Pesquisas Educacionais (In EP). Censo da Educação Básica. 2004. Disponível em: বhttp://www.inep.gov.br/basica/censo>. Acesso em: 23 mar. 2005.

BRAVERM AN , H. Trabalho e capital monopolista: a degradação do trabalho no século xx. 3. ed. Rio de Janeiro: LTC, 1987.

CARD O SO , T.M . Cultura da escola e profi ssão docente: inter-relações. 2001. Tese (D outorado) - Faculdade de Educação, Universidade Federal de M inas Gerais, Belo H orizonte.

CARVALH O, M .P. Trabalho docente e relações de gênero: algumas indagações. Revista Brasileira de Educação, São Paulo, n. 2, p. 77-84, maio/ jul. 1996. 
CORREA, V.M .A. Formação da consciência política do professor, em tempos de gl obalização e neoliberalismo. 1999. Tese (D outorado) - Universidade Federal Fluminense, Niterói.

COSTA, M .C.V. Trabalho docente e profissionalismo. Porto Alegre: Sulina, 1995.

EN GUITA, M .F. A ambigüidade da docência: entre o profissionalismo e a proletarização. Teoria \& Educação, Porto Alegre, n. 4, p. 41-61, 1991.

FERREIRA, R. Entre o sagrado e o profano: o lugar social do professor. Rio de Janeiro: Q uartet, 1998.

FID ALGO , F.S. Trabalho e carreira docente: contribuições teórico-metodológicas. Trabalho \& Educação, Belo H orizonte, n. 0, p. 95-109, jul./dez. 1996.

FIGUEIRA, F.G. D iálogos de um novo tempo. 1989. Tese (D outorado) Universidade de São Paulo, São Paulo.

FRIG OTTO, G. A produtividade da escola improdutiva: um (re)exame das relações entre educação e estrutura econômico-social e capitalista. São Paulo: Cortez; Campinas: Autores Associados, 1984.

GERALDI, C.M.G.; FIORENTINI, D.; PEREIRA, E.M.A. (O rg.). Cartografias do trabal ho docente: professor(a) - pesquisador(a). Campinas: M ercado de Letras, 1998.

H ABERM AS, J. Técnica e ciência como ideologia. Lisboa: Edições 70, 1968.

H AGUETTE, A. Educaçãa: bico, vocação ou profissão? Educação \& Socie dade, Campinas, v. 12, n. 38, p. 109-121, abr. 1991.

H ARVEY, D. Condição pós-moderna: uma pesquisa sobre as origens da mudança cultural. 9. ed. São Paulo: Loyola, 2000.

H YPÓ LIT O, A.L.M . Processo de trabalho na escola: algumas categorias para análise. Teoria \& Educação, Porto Alegre, n. 4, p. 3-21, 1991.

H YPÓ LITO , A.L. Processo de trabalho docente: uma análise a partir das relações de classe e gênero. 1994. Dissertação (M estrado) - Faculdade de Educação, Universidade Federal de M inas G erais, Belo H orizonte.

H YPÓ LITO , A.L. Trabalho docente: classe social e relações de gênero. Campinas: Papirus, 1997. 
Trabalho docente e capitalismo: um estudo crítico da produção acadêmica...

IASI, M .L. 0 dilema de Hamlet: 0 ser e o não ser da consciência. São Paulo: Viramundo, 2002.

LU GLI, R.S.G. U m estudo sobre o CPP (Centro do Professorado Paulista) e o movimento de organização dos professores (1964-1990). 1997. Dissertação (M estrado) - Universidade de São Paulo, São Paulo.

LU GO N , I.F. Professor sonâmbulo: é possível despertar?. 1994. Dissertação (M estrado) - Universidade Federal Fluminense, $N$ iterói.

M ARX, K. 0 capital. São Paulo: Abril Cultural, 1983. v. 1, t. 1.

M ARX, K. 0 capital. São Paulo: Abril Cultural, 1984. v. 1, t. 2.

M ARX, K. Capítulo VI inédito de 0 capital. São Paulo: M oraes, 1985.

M ARX, K.; EN GELS, F. A ideologia alemã: (I - Feuerbach). 4. ed. São Paulo: нucitec, 1984.

MEN DES, J.E. 0 trabalho na docência. In: Araujo N eto, A.E.; Pina, M .J.; Felisbino, S.C. (O rg.). Trabalho e educação face à crise global do capitalismo. Fortaleza: LCR, 2002.

MESZAROS, I. M arx: a teoria da alienação. Rio de Janeiro: Zahar, 1981.

M ESZAROS, I. Para além do capital. São Paulo: Boitempo, 2002.

M ORAES, M.C.M.; TORRIGLIA, P.L. Sentidos de ser docente e da construção de seu conhecimento. In: M oraEs, M .C.M . (O rg.). Iluminismo às avessas produção de conhecimento e políticas de formação docente. Rio de Janeiro: DP\& A, 2003.

N AJJAR, J.N .V. Q uestões sobre a proletarização docente, na cidade do Rio de Janeiro, a partir da fala de antigos professores. 1992. Dissertação (M estrado) - U niversidade Federal Fluminense, N iterói.

N UN ES, A.R.C. A natureza do trabalho docente como mediação da relação orgânica entre sindicato e escola. 1998. D issertação (M estrado) - Universidade Federal do Paraná, Curitiba.

N U N ES, M .0 . A instituição escolar pública capitalista: campo de práticas sociais distintas e produçõees ideológicas diferenciadas. 1990. Dissertação (M estrado) - Universidade Federal do Rio Grande do Sul, Porto Alegre. 
O LIVEIRA, D.A. (O rg.). Reformas educacionais na América Latina e os trabalhadores docentes. Belo H orizonte: Autêntica, 2003.

OZGA, J.; LAW N, M. 0 trabalho docente: interpretando o processo de trabalho do ensino. Teoria \& Educação, Porto Alegre, n. 4, p. 140-158, 1991.

PO LETTINI, A.F.F. M udança e desenvolvimento do professor: 0 caso de Sara. Revista Brasileira de Educação, São Paulo, n. 9, p. 88-98, set./dez. 1998.

QUELUZ, A.G. (O rient.); ALO N SO , M. (O rg.). 0 trabalho docente: teoria e prática. São Paulo: Pioneira, 1999.

RUBIN , I.I. A teoria marxista do valor. São Paulo: Polis, 1987.

SANT OS, C.M. A proletarização do trabalho docente: entre o mito, a realidade e a possibilidade. Trabalho \& Educação, Belo H orizonte, n. 4, p. 137-160, ago./dez. 1998.

SAN T O S, E. Identidade profissional docente: os ditos e os feitos. 2001. D issertação (M estrado) - U niversidade Federal do C eará, Fortal eza.

SAVIAN I, D. Educação: do senso comum à consciência filosófica. 12. ed. Campinas: Autores Associados, 1996.

SERRÃO, M .I.B. Superando a racionalidade técnica na formação: SOnho de uma noite de verão. In: PImenta, S. G.; Ghedin, E. (O rg.). Professor reflexivo no Brasil: gênese e crítica de um conceito. São Paulo: Cortez, 2002.

SILVA, M .V. Trabalho docente e gestão escolar: formação, deformação e transformação do educador. 1995. Dissertação (M estrado) - U niversidade Federal de U berlândia, U berlândia.

SI LVA, T.T. 0 que produz e o que reproduz em educação. Porto Alegre: Artes M édicas, 1992.

SO UZA, A.N. Sou professor, sim senhor!: representações do trabalho docente. Campinas: Papirus, 1996.

SO UZA, C.P. et al. M emória e autobiografia: formação de mulheres e formação de professoras. Revista Brasileira de Educação, São Paulo, n. 2, p. 61-76, maio/jul. 1996. 
Trabalho docente e capitalismo: um estudo crítico da produção acadêmica...

SO U ZA, O .L.D. Participação de professores em movimentos grevi stas: ressonâncias na organização do trabalho docente no cotidiano da escola pública. 1993. D issertação (M estrado) - Universidade Federal do Rio de Janeiro, Rio de Janeiro.

TAVARES, L.C. H eterogênese e educação: buscando universos de referência para o trabalho docente. 1996. D issertação (M estrado) - Universidade Federal do Rio Grande do Sul, Porto Alegre.

TEN FEN , W. 0 processo de (des)qualificação do professor. 1992. D issertação (M estrado) - U niversidade Federal de Santa Catarina, Florianópolis.

THERRIEN, A.T.S. Trabalho docente: uma incursão no imaginário social brasileiro. São Paulo: educ, 1998.

TITO, E.M.R.M. 0 processo de trabalho em uma escola pública de $1^{0}$ grau. 1994. Dissertação (M estrado) - Universidade Federal do Rio Grande do Sul, Porto Alegre.

TU M O LO , P.S. D a contestação à conformação: a formação sindical da CUT e a reestruturação capitalista. Campinas: Un ICAM P, 2002.

TUM OLO, P.S. Trabalho, vida social e capital na virada do milênio: apontamentos de interpretação. Educação \& Soci edade, Campinas, v. 24, n. 82, p. 159-178, abr. 2003.

TUMOLO, P.S. 0 trabalho na forma social do capital e o trabalho como princípio educativo: uma articulação possível? Educação \& Sociedade, Campinas, v. 26, n. 90, p. 239-265, 2005

VIAN N A, C.P. O s nós do "nós": crise e perspectiva da ação coletiva docente em São Paulo. São Paulo: Xamã, 1999.

VIAN N A, C.P. A produção acadêmica sobre organização docente: ação coletiva e relação de gênero. Educação \& Sociedade, Campinas, v. 22, n. 77, p. 100-130, dez. 2001.

VIEIRA, J.S. U m negócio chamado educação: qualidade total, trabalho docente e identidade. Pelotas: Seiva, 2004.

WENZEL, R.L. O professor e o trabalho abstrato: uma análise da (des)qualificação do professor. 1991. D issertação (M estrado) - Universidade Federal de Santa Catarina, Florianópolis. 